\title{
Simultaneous determination of ten illegal azo dyes in feed by ultra-high performance liquid chromatography tandem mass spectrometry
}

\author{
Marta Piątkowska, Piotr Jedziniak, Małgorzata Olejnik, \\ Konrad Pietruk, Jan Żmudzki, Andrzej Posyniak \\ Department of Pharmacology and Toxicology, \\ National Veterinary Research Institute, 24-100 Pulawy, Poland \\ marta.piatkowska@piwet.pulawy.pl
}

Received: March 29, 2017

Accepted: August 25, 2017

\begin{abstract}
Introduction: The paper presents the method of simultaneous determination of 10 illegal azo dyes in feed by ultra-high performance liquid chromatography coupled with tandem mass spectrometry technique. Material and Methods: The dyes were extracted with hexane, evaporated to dryness, and analysed. Separation was achieved in 7 min in a gradient elution using acetonitrile (A) and $0.1 \%$ formic acid (B) as a mobile phase. Results: The validation results showed the repeatability of the method, which was evaluated at three levels $(50,500$, and $5,000 \mu \mathrm{g} / \mathrm{kg})$. All the matrix calibration curves for the working ranges were linear $\left(\mathrm{R}^{2} 0.9904\right.$ to 1.0$)$, the repeatability was between $2.1 \%$ and $24 \%$, and recoveries ranged from $77.9 \%$ to $120 \%$. The LOD and LOQ were at $1-2$ and $5-10 \mu \mathrm{g} / \mathrm{kg}$ for different dyes, respectively. Furthermore, the method was applied in the homogeneity tests of the in-house prepared feed containing Sudan I at the levels of $0.5,5$, and $50 \mathrm{mg} / \mathrm{kg}$. Conclusions: A sensitive, selective, and fast multiresidue method was successfully developed and validated. Its robustness was confirmed by the analysis of an experimental feed containing Sudan I.
\end{abstract}

Keywords: feed, Sudan dyes, azo dyes, illegal dyes, LC-MS/MS.

\section{Introduction}

Azo dyes (like Sudan I-IV, Sudan Red G, Sudan Red 7B, Sudan Orange G, Para Red, toluidine Red, and Citrus Red) are synthetic fat-soluble dyes used in the industry on a large scale. They are classified as Group 3 carcinogens by the International Agency for Research on Cancer (7) and are prohibited for use in the food industry. Azo dyes may be reduced to toxic aromatic amines, e.g. Sudan I and III can undergo the enzymatic reactions and give aniline, Sudan II - 2,4dimethylaniline, Sudan IV - o-toluidine, and Para Red - $p$-nitroaniline (14).

Any amount of these dyes in food can be hazardous to human health. Despite this fact, they are still detected in food products, mainly those containing spices like chilli, curry, turmeric, or paprika. Because these products fade during storage, intensely red or orange dyes are added to provide a brighter and deeper colour, evocative of better quality and freshness. The presence of illegal dyes in spices is such a significant issue in food safety that the European Union introduced obligatory control for the presence of Sudan dyes I-IV in chilli peppers, chilli products, turmeric, and palm oil imported from all of the third countries (3).

On the other hand, red pepper, powdered or liquid (oleoresins), is used as feed additive to enhance the egg yolk colour or produce a golden brown colour of broilers skin. In the oleoresins, Rodamine B was the most commonly present industrial dye and Sudan I was present at the level of $10-120 \mu \mathrm{g} / \mathrm{kg}$ (4). However, the contamination was not necessarily the effect of adulteration of the paprika used to produce the oleoresin. It may have resulted from the use of red packages for drying, storage, and transport of peppers, as well as the use of lubricants containing Sudan I in the machines for paprika grinding and preparation of oleoresins (4). Furthermore, research on natural contamination has demonstrated that the combination of Sudan I-contaminated soils and application of 
Sudan I-containing agronomic materials constitutes a major source of $0.18-2.52 \mu \mathrm{g} / \mathrm{kg}$ levels of Sudan I in fruit during the growth period (8).

In 2006, in China, there were reports of the use of industrial dyes mixed with feed to enhance the egg yolk colour. Hen and duck eggs were reported to contain Sudan IV dye at the level of up to $300 \mu \mathrm{g} / \mathrm{kg}$ (1). The source of the dye in eggs is not precisely known. In 2013, Chen et al. (2) screened the food of animal origin for the presence of Sudan I-IV azo dyes and confirmed the presence of Sudan I in two swine muscles samples, one swine liver, and one egg sample. They reported concentrations ranging from 2.47 to $6.21 \mu \mathrm{g} / \mathrm{kg}$ without specifying which matrices they matched. Because Sudan azo dyes are still found in food of animal origin, simple and accurate confirmatory methods for the determination of illegal dyes in feed products are needed to ensure health and safety of both animals and consumers. Although there are plenty of analytical methods suitable for the determination of illegal dyes in spices, to the authors' best knowledge, only few methods have been developed for the determination of Sudan dyes in feeds.

This paper presents the method developed for the simultaneous determination of 10 illegal dyes in feeds. The method was validated and verified using in-house prepared experimental feed for laying hens containing $1 \%$ of red pepper contaminated with a Sudan I dye.

\section{Material and Methods}

Chemicals and reagents. Acetonitrile $(\mathrm{ACN})$, methanol, and formic acid (99.5\%) (all HPLC grade) were provided by J.T. Baker (USA). Dimethyl sulfoxide (DMSO), hexane, acetone, ethyl acetate, ethanol, chloroform, and analytical standards of Sudan I, Sudan I-d5, Sudan II, Sudan III, Sudan IV, Sudan Red 7B, Sudan Red G, Sudan Orange G, Citrus Red, toluidine Red, and Para-Red were purchased from Sigma-Aldrich (Germany). Water was purified through a Milli-Q plus system from Millipore (USA) and PTFE syringe filters $(0.2 \mu \mathrm{m}, 25 \mathrm{~mm})$ were received from Restek (USA).

Preparation of standard solutions. The stock standard solutions $(1,000 \mu \mathrm{g} / \mathrm{mL})$ of Citrus Red, Sudan I, Sudan I-d5 (internal standard), Sudan II, Sudan Orange G, and Sudan Red G were prepared by weighing appropriate amount of substances and dissolving in acetonitrile, and Sudan III, Sudan IV, Sudan Red 7B, toluidine Red, and Para Red in acetone. All stock solutions were kept in the dark at a temperature below $-18^{\circ} \mathrm{C}$ for six months. A solution of an internal standard was prepared separately.

Working standard solutions of dyes were prepared by dissolving appropriate amounts of standard solutions with acetonitrile and kept in the dark at $4-6^{\circ} \mathrm{C}$ for three months.
Ultra-performance liquid chromatographymass spectrometry. The LC-MS/MS system consisted of a Shimadzu Nexera X2 UHPLC liquid chromatograph (Shimadzu, Japan) coupled with an 8050 triple quadrupole detector (Shimadzu, Japan), controlled by LabSolution 5.60 SP2 software. The experiments were conducted in the positive electrospray mode using Luna C18 analytical column $(50 \times 2.0 \mathrm{~mm}, 3 \mu \mathrm{m})($ Phenomenex, USA) with a C18 guard cartridge operated at $40^{\circ} \mathrm{C}$. The mobile phase consisted of acetonitrile (A) and $0.1 \%$ formic acid (B). The gradient was: $50 \%$ A (0 to $1.5 \mathrm{~min}), 80 \%$ A (1.51 to $2.5 \mathrm{~min}), 100 \% \mathrm{~A}$ (2.51 to $4 \mathrm{~min}$, maximum to $5 \mathrm{~min}$ ), $50 \%$ A (5 to $5.01 \mathrm{~min}$, maximum to $7 \mathrm{~min}$ ). The flow rate was $400 \mu \mathrm{L} / \mathrm{min}$ and the injection volume was $10 \mu \mathrm{L}$. The mass spectrometer working parameters (ionisation mode, capillary voltage, source temperature, fragmentary voltage, and collision energy) were optimised. The fragmentation reactions used for monitoring were selected on the basis of their significance in the production spectra. The analytes were quantified using the selected reactions monitoring (SRM) mode. For each analyte, at least two of the most abundant transitions were monitored.

Sample preparation equipment. Feed samples were ground using a mill (Glen Mills Inc, USA) and weighed in $50 \mathrm{~mL}$ Nunc $^{\mathrm{TM}}$ conical sterile polypropylene centrifuge tubes (Thermo Fisher Scientific Inc., USA). A Sonorex ultrasonic bath (Bandelin Electronic, Germany) operating at $30^{\circ} \mathrm{C}$ and shaker mixer set as $200 \mathrm{rpm}$ (Barnstead, LabX, Canada) were used to enhance the extraction. An MPW-6K15 (MPW Med. Instruments, Poland) centrifuge set at $4,500 \mathrm{rpm}, 4^{\circ} \mathrm{C}$ was used to remove the precipitated proteins. A VLM Eva EC1/EC2L (VLM, Germany) nitrogen evaporator set at $45^{\circ} \mathrm{C}$ was used for sample evaporation.

Sample preparation. Feed sample (3 g) was weighed into a centrifuge tube and a mixed working standard solution of 10 dyes was added. Next, $30 \mathrm{~mL}$ of extracting agents was added and the samples were vortexed. They were extracted using a shaker mixer (200 rpm, $30 \mathrm{~min}$ ) and then ultrasonication was applied $\left(15 \mathrm{~min}, 30^{\circ} \mathrm{C}\right)$. After the centrifugation $(10 \mathrm{~min}$, $\left.4,500 \mathrm{rpm}, 4^{\circ} \mathrm{C}\right), 500 \mu \mathrm{L}$ of extract was placed in a glass tube for evaporation. The dry residues were reconstituted with $500 \mu \mathrm{L}$ of acetonitrile saturated with hexane: DMSO (80:20), vortexed, and filtered through $0.2 \mu \mathrm{m}$ PTFE syringe filters. Finally, $10 \mu \mathrm{L}$ of each sample was injected into LC-MS/MS system for analysis.

Method validation. The specificity was checked by analysing 20 different blank feed samples to evaluate possible interferences. The method repeatability was evaluated by the repeated analysis of feed samples $(n=18)$ fortified with analytes at concentrations of 50, 500, and $5,000 \mu \mathrm{g} / \mathrm{kg}$ (and $50 \mathrm{mg} / \mathrm{kg}$ for Sudan I) during one day. The recoveries 
were evaluated in the same experiment as repeatability. To perform validation, two matrix-matched calibration curves were prepared: $10,50,100$, and $500 \mu \mathrm{g} / \mathrm{kg}$, and $0.5,1,3$, and $5 \mathrm{mg} / \mathrm{kg}$ for all analytes. The linearity ranged from 0.9991 to 1.0 and from 0.9904 to 0.9998 for the two working ranges, respectively. The additional curve for Sudan I at 25, 50, and $75 \mathrm{mg} / \mathrm{kg}$ with $\mathrm{R}^{2} 0.9981$ was prepared to validate Sudan I at the concentration of $50 \mathrm{mg} / \mathrm{kg}$ feed. Limits of detection and quantification were calculated as well based on signal-to-noise ratio of blank samples (LOD $\mathrm{S} / \mathrm{N}=3$, LOQ S/N =6).

Additionally, the matrix effect was evaluated by preparing six pre- and post-spiked samples at the level of $500 \mu \mathrm{g} / \mathrm{kg}$ and calculated using calibration curve at the concentration of 250,500 , and $750 \mu \mathrm{g} / \mathrm{kg}$. Three very simple equations (1), (2), and (3) were used to determine the matrix effect (ME), recovery of extraction (RE), and overall process efficiency (PE) (10).

Equation (1)

$$
M E(\%)=\frac{B}{A} \times 100
$$

Equation (2)

$$
R E(\%)=\frac{C}{B} x 100
$$

Equation (3)

$$
P E(\%)=\frac{C}{A} \times 100=\frac{M E \times R E}{100},
$$

where A is the peak area of the analyte(s) recorded for the standard solution, B is the peak area of the analyte(s) recorded for the sample spiked with the target compound(s) after extraction, and $\mathrm{C}$ is the peak area of the analyte(s) recorded for the sample spiked with the target compound(s) before extraction.

Preparation of experimental feed. A total of $40 \mathrm{~kg}$ of feed was prepared for three concentrations of Sudan I. Complete feed for laying hens (DJ-Nioska, Agropol S.J., Motycz, Poland) was used. Additionally, $1 \%(400 \mathrm{~g})$ of red pepper was added to the experimental feed. Both red pepper and feed were examined for the presence of illegal dyes before they were used in the experiment.

Experimental feed containing $0.5 \mathrm{mg} / \mathrm{kg}$ of Sudan I was prepared as follows: $20 \mathrm{mg}$ of Sudan I added to $9.98 \mathrm{~g}$ of red pepper resulted in $10 \mathrm{~g}$ of red pepper containing Sudan I at a concentration of $2 \mathrm{~g} / \mathrm{kg}$. Next, $10 \mathrm{~g}$ of premix was mixed with $390 \mathrm{~g}$ of red pepper, resulting in concentration of $50 \mathrm{mg} / \mathrm{kg}$ of Sudan I. Then, $400 \mathrm{~g}$ of red pepper was added to feed, resulting in $2 \mathrm{~kg}$ of feed with concentration of $10 \mathrm{mg} / \mathrm{kg}$ of Sudan I. That premix was used to prepare $40 \mathrm{~kg}$ of feed containing Sudan I at concentration of $0.5 \mathrm{mg} / \mathrm{kg}$.

The experimental feeds containing Sudan I at the levels of 5 and $50 \mathrm{mg} / \mathrm{kg}$ were prepared in the same way.
Homogeneity tests. To check the homogeneity of prepared feeds, 10 feed samples at each concentration were analysed in duplicates according to the presented protocol. Cochran test for the double analysis in the homogeneity studies was used to detect outlying results (confidence level 95\%). Finally, a test of 'sufficient homogeneity' based on an analysis of variance was performed. If the variance sampling was lower than the boundary, the reference material was considered to be homogeneous (13).

\section{Results}

The optimised instrument conditions including mass fragmentation patterns (parent ion - Q1 and daughter ions - Q3) as well as collision energy (CE) are presented in Table 1.

Table 1. Tandem mass spectrometry parameters

\begin{tabular}{llll}
\hline Analyte & Q1 & Q3 & CE (eV) \\
\hline ESI $^{+}$ & & & \\
Sudan I & 249 & $93 / 128$ & $25 / 25$ \\
Sudan II & 277 & $121 / 106$ & $21 / 41$ \\
Sudan III & 353 & $77 / 91$ & $28 / 38$ \\
Sudan IV & 381 & $106 / 225$ & $33 / 16$ \\
Sudan Red G & 279 & $123 / 108$ & $17 / 33$ \\
Sudan Orange G & 215 & $93 / 128$ & $24 / 15$ \\
Sudan Red 7B & 380 & $183 / 115$ & $16 / 48$ \\
Citrus Red & 309 & $152 / 138$ & $17 / 33$ \\
Para Red & 294 & $128 / 277$ & $27 / 15$ \\
Toluidine Red & 308 & $156 / 128$ & $17 / 28$ \\
Sudan I-d5 & 254 & 98 & 25 \\
\hline
\end{tabular}

$\mathrm{ESI}^{+}$- positive electrospray ionization, CE - collision energy, $\mathrm{Q} 1$ - parent ion, Q3 - daughter ions

For the separation of the analytes, mobile phase consisting of acetonitrile and $0.1 \%$ formic acid was used to achieve the chromatographic separation of all dyes in 7 min (Fig. 1).

To develop an extraction protocol, feed samples ( $3 \mathrm{~g}$ ) were weighed into a centrifuge tube and mixed working standard solution of 10 dyes was added (resulted fortification level was $50 \mu \mathrm{g} / \mathrm{kg}$ ). Then, $30 \mathrm{~mL}$ of testing extracting agents were added and samples were vortexed. The solvents mixtures were: acetonitrile saturated with hexane 9:1 (v/v), acetone/acetonitrile 50:50 (v/v), acetone, ethyl acetate, acetonitrile/chloroform 8:2 (v/v), ethanol, acetonitrile, acetone/hexane 1:3 (v/v), hexane, and methanol. Performance levels of the extraction efficiency are presented using the example of Sudan I in Fig. 2.

During the method validation the matrix effect was also evaluated. Calculated matrix effect ranged from $71 \%$ to $109 \%$ (Fig. 3).

The homogeneity of all three prepared feeds administered to animals was examined and the results of various analyses are summarised in Table 2. 


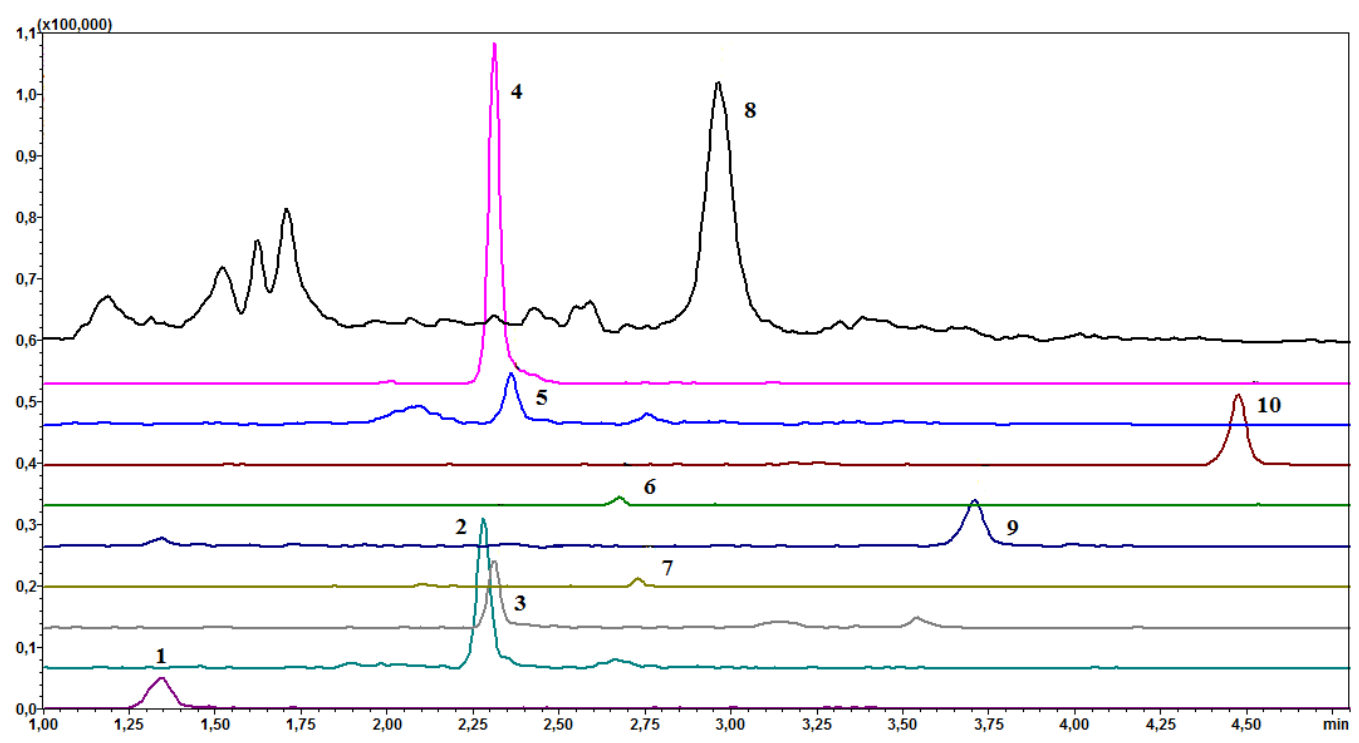

Fig. 1. Chromatograms of feed sample fortified with 10 dyes at $10 \mu \mathrm{g} / \mathrm{kg}$ and corresponding retention times (RT, min): 1. Sudan Orange G (1.343), 2. Sudan Red G (2.280), 3. Toluidine Red (2.311), 4. Citrus Red (2.312), 5. Sudan I (2.362), 6. Sudan IV (2.676), 7. Para Red (2.731), 8. Sudan II (2.963), 9. Sudan III (3.709), 10. Sudan Red 7B (4.476)

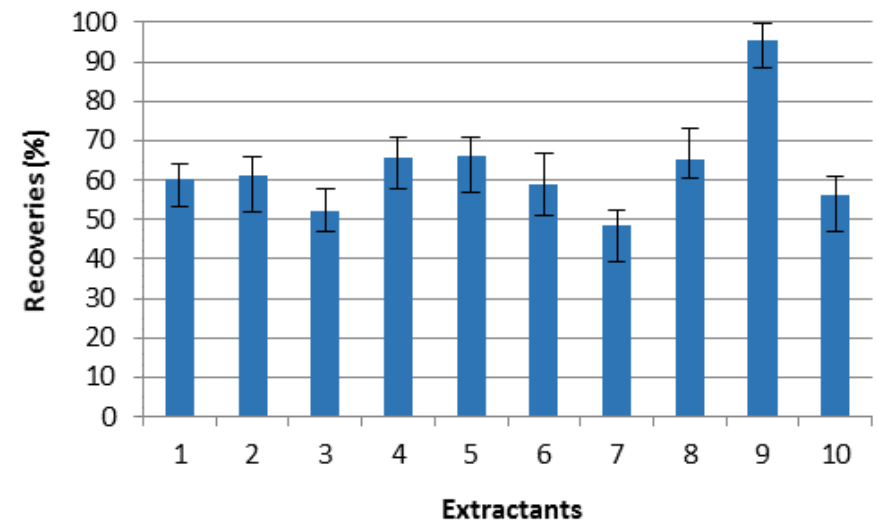

Fig. 2. Recoveries of Sudan I from the fortified feeds $(n=3)$ using the following solvents: (1) acetonitrile saturated with hexane 9:1 (v/v), (2) acetone/acetonitrile $50: 50(\mathrm{v} / \mathrm{v}),(3)$ acetone, (4) ethyl acetate, (5) acetonitrile/chloroform 8:2 (v/v), (6) ethanol, (7) acetonitrile, (8) acetone/hexane 1:3 (v/v), (9) hexane, (10) methanol

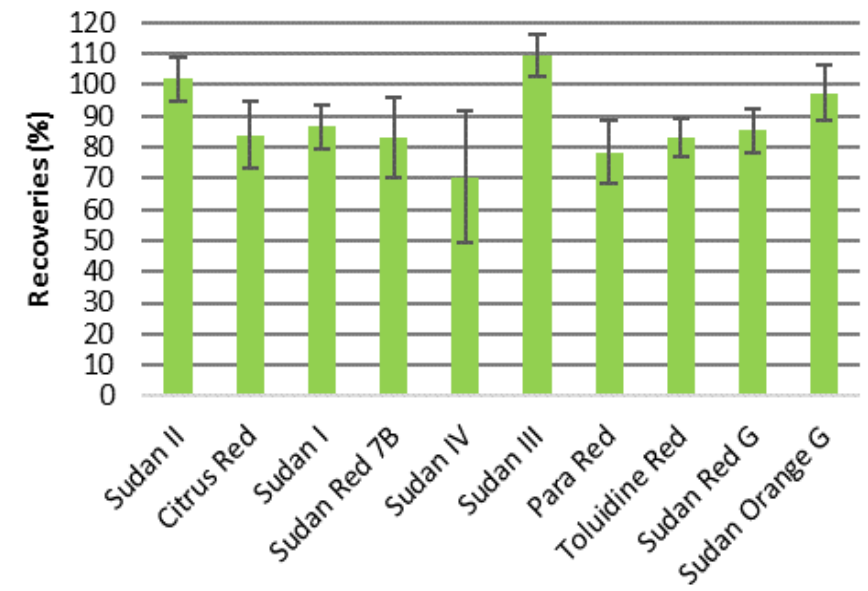

Fig. 3. Matrix effect for individual azo-dyes 
Table 2. The results of individual analyses of feed containing Sudan I prepared for laying hens

\begin{tabular}{cccccc}
\hline \multicolumn{7}{c}{ Concentration determined $(\mathrm{mg} / \mathrm{kg})$} \\
\hline \multicolumn{7}{c}{$0.5 \mathrm{mg} / \mathrm{kg}$} & \multicolumn{2}{c}{$5 \mathrm{mg} / \mathrm{kg}$} & \multicolumn{3}{c}{$50 \mathrm{mg} / \mathrm{kg}$} \\
\hline 0.46 & 0.52 & 4.98 & 4.96 & 41.0 & 39.3 \\
\hline 0.45 & 0.49 & 4.92 & 5.05 & 39.8 & 47.5 \\
\hline 0.48 & 0.47 & 4.97 & 4.97 & 49.4 & 45.6 \\
\hline 0.51 & 0.47 & 4.98 & 4.93 & 48.2 & 42.1 \\
\hline 0.44 & 0.47 & 4.98 & 4.99 & 41.9 & 42.1 \\
\hline 0.45 & 0.40 & 4.98 & 4.97 & 39.5 & 40.4 \\
\hline 0.37 & 0.43 & 4.90 & 4.97 & 38.4 & 50.4 \\
\hline 0.41 & 0.45 & 5.01 & 4.98 & 37.6 & 39.2 \\
\hline 0.45 & 0.43 & 4.95 & 4.93 & 42.2 & 42.3 \\
\hline 0.41 & 0.46 & 4.97 & 4.96 & 38.1 & 37.1 \\
\hline \multicolumn{7}{c}{ Average } \\
\hline \multicolumn{7}{c}{$4.97 \mathrm{mg} / \mathrm{kg}$} \\
\hline
\end{tabular}

\section{Discussion}

Although a lot of attention is paid to the presence of illegal dyes in food, there are not many methods for their determination in feed. Acquiring reliable analytical method is important in terms of the prevention against the dyes entering the food chain.

Optimisation of chromatographic and mass spectrometry conditions is necessary to develop a sensitive method and obtain a possibly short overall analysis time. This study was conducted using ESI positive ionisation source, which resulted in the production of high intensity peaks for the selected dyes and good linearity in the regression curves. Chromatographic analysis was carried out using gradient elution to obtain an adequate signal response and sharp, symmetric peak shapes. To achieve short chromatographic run, the selection of a chromatographic column was the key parameter. Because of the high retention of dyes in this experiment, a short column of $50 \mathrm{~mm}$ in length with $3 \mu \mathrm{m}$ particle size was chosen to separate 10 dyes in 7 min (Fig. 1).

Establishment of an efficient extraction procedure is one of the main and most timeconsuming steps during method development. At first, feed samples have to be precisely ground to ensure the sample homogeneity and better extraction efficiency. Secondly, samples are a complex material composed of multiple ingredients, such as proteins, vitamins, oils etc., which disturbs analysis. In this experiment, to evaluate extraction efficiency, a technique of solid-liquid extraction using several solvents and their mixtures was tested. Usually feed samples are mixed with water for better isolation of the analytes. In this experiment, as the dyes are hydrophobic agents, this step was omitted. The results were compared by measuring the recoveries of analytes obtained after extraction using various solvents $(n=3)$. The highest efficiency was achieved when hexane was used (Fig. 2). Similar results were previously reported (6), but these authors explained this fact as likely to be a result of an interference of polar solvent to the hydrogen bonding based molecular imprinted polymer (MIP) coating they have optimised.

Feeds are a complicated matrix from the analytical point of view, because the salts, carbohydrates, and other compounds they contain interfere with the determined analytes. Therefore, in the developed method samples were extracted using the technique of solid-liquid extraction with hexane a solvent of low polarity. Other authors extracted the feed samples with acetonitrile $(5,9)$ or hexane $(6)$, applied sample purification using SPE columns with an amine (12 azo dyes) (5) or octadecyl sorbent (5 azo dyes) (9), and also used molecularly imprinted sorbents (4 azo dyes) (6). In the presented method, no additional sample cleanup was necessary. After the evaporation step, the dry residues were reconstituted in acetonitrile saturated with hexane and DMSO, due to the difficulties with their complete dissolution in mobile phase. After simple syringe filtration, the resulted extracts injected into the instrument were sufficiently clean for UPLC-MS/MS analysis.

During the method validation, no peaks were observed in blank feed samples at the retention times corresponding to the analytes. The repeatability was in the range of $2.1 \%$ to $24 \%$, while the recoveries ranged from $77.9 \%$ to $120 \%$ and are comparable with the previously developed methods $(5,6,9)$. The limits of detection (LOD) and limits of quantification (LOQ) were calculated as $1 \mu \mathrm{g} / \mathrm{kg}$ and $5 \mu \mathrm{g} / \mathrm{kg}$ for Sudan II, Sudan Red 7B, Citrus Red, and Toluidine Red, and 2 and $10 \mu \mathrm{g} / \mathrm{kg}$ for other dyes. The levels of LODs are similar to other methods but the sample preparation step is shorter. The working range is the widest among all the methods proposed so far. It allows the determination of the dyes from trace residual levels up to $5 \mathrm{mg} / \mathrm{kg}$ (10 dyes) and $50 \mathrm{mg} / \mathrm{kg}$ (Sudan I). The validation parameters of the newly developed as well as previously described methods are presented in Table 3. 
Table 3. Percentage recoveries (R, \%), relative standard deviations (CV, \%), limits of detection (LOD), and limits of quantification (LOQ) of the methods for the determination of azo dyes in feed

\begin{tabular}{|c|c|c|c|c|c|c|c|c|c|c|c|c|}
\hline \multirow{4}{*}{ Analyte } & \multicolumn{4}{|c|}{ Current study $(\mathrm{n}=18)$} & \multicolumn{3}{|c|}{ Hu et al. $(6)(n=10)$} & \multicolumn{2}{|c|}{ Liu et al. $(9)(n=6)$} & \multicolumn{3}{|c|}{ Hou et al. $(5)(\mathrm{n}=5)$} \\
\hline & \multicolumn{4}{|c|}{$\begin{array}{c}\text { LOD }(1-2), \text { LOQ } 5-10 \\
(\mu \mathrm{g} / \mathrm{kg})\end{array}$} & \multicolumn{3}{|c|}{$\begin{array}{l}\text { LOD } 2.8-4.5 \\
(\mu \mathrm{g} / \mathrm{kg})\end{array}$} & \multicolumn{2}{|c|}{$\begin{array}{l}\text { LOQ } 0.01-5.61 \\
(\mu \mathrm{g} / \mathrm{kg})\end{array}$} & \multicolumn{3}{|c|}{$\begin{array}{c}\text { LOD: 6-20, LOQ 20-200 } \\
(\mu \mathrm{g} / \mathrm{kg})\end{array}$} \\
\hline & \multicolumn{2}{|c|}{$\begin{array}{l}\mathrm{R}, \mu \mathrm{g} / \mathrm{kg} \\
\mathrm{CV}, \%\end{array}$} & \multicolumn{2}{|c|}{$\begin{array}{l}\mathrm{R}, \mathrm{mg} / \mathrm{kg} \\
\mathrm{CV}, \%\end{array}$} & \multicolumn{3}{|c|}{$\begin{array}{c}\mathrm{R}, \mu \mathrm{g} / \mathrm{kg} \\
\mathrm{CV}, \%\end{array}$} & $\begin{array}{l}\mathrm{R}, \mu \mathrm{g} / \mathrm{kg} \\
\mathrm{CV}, \%\end{array}$ & $\begin{array}{c}\mathrm{R}, \mathrm{mg} / \mathrm{kg} \\
\mathrm{CV}, \%\end{array}$ & \multicolumn{3}{|c|}{$\begin{array}{c}\mathrm{R}, \mu \mathrm{g} / \mathrm{kg} \\
\mathrm{CV}, \%\end{array}$} \\
\hline & 50 & 500 & 5 & 50 & 25 & 100 & 250 & 100 & 1 & 200 & 400 & 800 \\
\hline \multirow{2}{*}{ Sudan I } & 93.2 & 89.2 & 106 & 88 & 89.3 & 93.6 & 97.4 & 84.1 & 89.1 & 76.1 & 76.8 & 74.4 \\
\hline & 4.7 & 4.6 & 2.9 & 9.5 & 6.2 & 4.6 & 2.6 & 3.6 & 6.0 & 6.3 & 5.9 & 6.0 \\
\hline \multirow{2}{*}{ Sudan II } & 89.7 & 119 & 102 & \multirow{2}{*}{-} & 87.4 & 94.5 & 95.9 & 110 & 96.0 & 72.2 & 70.4 & 76.8 \\
\hline & 7.7 & 5.2 & 7.6 & & 7.3 & 6.3 & 2.9 & 9.0 & 8.8 & 8.1 & 8.6 & 4.2 \\
\hline \multirow{2}{*}{ Sudan III } & 109 & 120 & 111 & \multirow{2}{*}{-} & 86.4 & 93.6 & 95.3 & 108.0 & 137 & 80.4 & 85.5 & 91.0 \\
\hline & 8.0 & 4.5 & 9.2 & & 5.7 & 4.6 & 4.2 & 11 & 5.4 & 4.5 & 3.9 & 4.2 \\
\hline \multirow{2}{*}{ Sudan IV } & 77.9 & 108 & 83.9 & \multirow{2}{*}{ - } & 84.6 & 92.4 & 94.2 & 98.3 & 100 & 90.7 & 82.5 & 85.9 \\
\hline & 12 & 5.2 & 14 & & 7.1 & 5.8 & 3.8 & 5.2 & 13 & 10 & 6.6 & 4.8 \\
\hline \multirow{2}{*}{ Sudan Red G } & 100 & 103 & 104 & \multirow[b]{2}{*}{-} & \multirow[b]{2}{*}{-} & \multirow{2}{*}{-} & \multirow{2}{*}{ - } & 114 & 93.7 & \multirow{2}{*}{ - } & \multirow{2}{*}{-} & \multirow{2}{*}{-} \\
\hline & 4.9 & 5.8 & 3.0 & & & & & 5.2 & 6.5 & & & \\
\hline Sudan $\mathrm{B}$ & - & 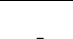 & - & - & - & - & 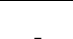 & 89.3 & 99.1 & - & 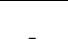 & 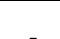 \\
\hline sudan D & - & - & - & - & - & - & - & 5.7 & 8.4 & - & - & - \\
\hline Sudan Orange $\mathrm{G}$ & 95.5 & 114 & 95 & & & & & 61.5 & 60.0 & & & \\
\hline suaan Urange $G$ & 4.6 & 6.5 & 4.0 & - & - & - & - & 5.6 & 6.6 & - & - & - \\
\hline Sudan Red 7B & 90.4 & 119 & 99.4 & & & & - & 95.7 & 119 & - & 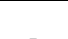 & - \\
\hline sudan Ked /D & 24 & 9.2 & 8.3 & - & - & - & - & 7.6 & 13 & - & - & - \\
\hline Citrus Red & 95.6 & 88.1 & 98.7 & - & - & - & - & - & - & - & - & - \\
\hline Citus Ked & 5.2 & 10 & 2.1 & - & - & - & - & - & - & - & - & - \\
\hline Para Red & 79.8 & 110 & 96.5 & - & - & & - & 86.7 & 72.5 & 64.8 & 62.7 & 66.4 \\
\hline Fага ке & 9.2 & 4.0 & 4.0 & - & - & - & - & 4.8 & 7.7 & 8.7 & 6.0 & 4.8 \\
\hline Toluidine Red & 98.2 & 92.5 & 80.8 & - & - & - & - & 110 & 87.2 & - & - & - \\
\hline Ioluiame Ked & 8.0 & 24 & 8.6 & - & - & - & - & 8.0 & 11 & - & - & - \\
\hline & & & & & & & & 139 & 103 & & & \\
\hline Rhodamine B & - & - & - & - & - & - & - & 14 & 9.2 & - & - & - \\
\hline Rhodamine 6G & - & - & - & - & - & - & - & 106 & 93.6 & _ & - & - \\
\hline 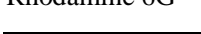 & - & - & - & - & - & - & - & 5.0 & 13 & - & - & - \\
\hline
\end{tabular}

The usefulness of the developed method was confirmed by conducting the homogeneity tests of the prepared experimental feed for laying hens. The feed was prepared to investigate the transfer of a genotoxic Sudan I to eggs after feeding the hens with feed containing red pepper contaminated with Sudan I (Fig. 4).

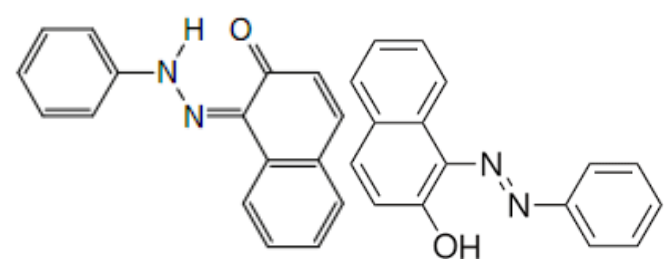

Fig. 4. Structural formula of Sudan I (1-phenylazo-2-naphthol)

During the evaluation of the homogeneity, the Cochran test results showed no outliers (confidence level 95\%) for double analysis. 'Sufficient homogeneity' test showed that the material was homogeneous and could be used in the experiment.

In conclusion, a sensitive, selective, and fast multiresidue method for the simultaneous determination of 10 illegal dyes in feed has been developed. The method was successfully validated and its usefulness was confirmed by conducting the homogeneity tests of the prepared experimental feed containing Sudan I. The developed method could be used to control the presence of illegal dyes in feeds.

Conflict of Interests Statement: The authors declare that there is no conflict of interests regarding the publication of this article.

Financial Disclosure Statement: This work was financed by grant of the National Science Centre "Sonata" 2012/07/D/NZ7/03242.

Animal Rights Statement: None required.

Acknowledgements: Many thanks to Maciej Durkalec, $\mathrm{PhD}$, for technical help with the preparation of experimental feed and to Ewelina Patyra, $\mathrm{PhD}$, for sharing the knowledge of feed analysis.

\section{References}

1. Center for Food Safety, the Government of the Hong Kong Special Administrative Region of the People's Republic of China: http://www.cfs.gov.hk Accessed on 2017.02.13.

2. Chen D., Li X., Tao Y., Pan Y., Wu Q., Liu Z., Peng D., Wang X., Huang L., Wang Y., Yuan Z.: Development of a liquid 
chromatography-tandem mass spectrometry with ultrasoundassisted extraction method for the simultaneous determination of Sudan dyes and their metabolites in the edible tissues and eggs of food producing animals. J Chromatogr B 2013, 939, 45-50.

3. Commission Regulation (EC) No 669/2009 of 24 July 2009 implementing Regulation (EC) No 882/2004 of the European Parliament and of the Council as regards the increased level of official controls on imports of certain feed and food of nonanimal origin and amending Decision 2006/504/EC. Official J., L 194, 11.

4. Hoenicke K.: Detection of low amounts of Sudan dyes and other illegal dyes in food and oleoresins. Analytical artefact or crosscontamination? AOAC Europe Section - International Workshop "Foods to Dye for", 7 November 2006.

5. Hou X., Li Y., Wu G., Wang L., Hong M., Wu Y.: Determination of para red, Sudan dyes, canthaxanthin, and astaxanthin in animal feeds using UPLC. J Chromatogr Sci 2010, $48,22-25$.

6. Hu X., Cai Q., Fan Y., Ye T., Cao Y., Guo C.: Molecularly imprinted polymer coated solid-phase microextraction fibers for determination of Sudan I-IV dyes in hot chilli powder and poultry feed samples. J Chromatogr A 2012, 1219, 39-46.

7. IARC: Monographs on the evaluation of carcinogenic risk of chemicals to some aromatic azo compounds. Lyon 1975, 8, 41.

8. Lian Y., Gao W., Zhou L., Wu N., Lu Q., Han W., Tie X.: Occurrence of Sudan I in paprika fruits caused by agricultural environmental contamination. J Agric Food Chem 2014, 62, 4072-4076.

9. Liu R., Hei W., He P., Li Z.: Simultaneous determination of fifteen illegal dyes in animal feeds and poultry products by ultrahigh performance liquid chromatography tandem mass spectrometry. J Chromatogr B 2011, 879, 2416-2422.

10. Matuszewski B.K., Constanzer M.L., Chavez-Eng C.M.: Matrix effect in quantitative LC/MS/MS analyses of biological fluids: a method for determination of finasteride in human plasma at picogram per milliliter concentrations. Anal Chem 1998, 70, 882-889.

11. Piatkowska M., Olejnik M., Jedziniak P., Zmudzki J: The transfer of a genotoxic and carcinogenic azo-dye Sudan I to eggs after feeding of laying hens with contaminated feed. Eurotox, 13-16 September 2015, Porto, Portugal.

12. Thompson M., Ellision S.L.R., Wood R.: The international harmonized protocol for the proficiency testing of analytical chemistry laboratories. Pure Appl Chem 2006, 78, 145-196.

13. Thompson M.: Test for 'sufficient homogeneity' in a reference material. 2008, Available on 2015.04.29.: http://www.rsc.org/ images/homogeneity-test-technical-brief-17A_tcm18-214886.pdf.

14. Xu H., Heinze T.M., Paine D.D., Cerniglia C.E., Chen H.: Sudan azo dyes and Para Red degradation by prevalent bacteria of the human gastrointestinal tract. Anaerobe 2010, 16, 114-119. 